\title{
Heat Stress Leads to Poor Fruiting Mainly Due to Inferior Pollen Viability and Reduces Shoot Photosystem II Efficiency in "Da Hong" Pitaya
}

\author{
Yu-Chun Chu ${ }^{1,2}$ and Jer-Chia Chang ${ }^{1, *}$
}

1 Department of Horticulture, National Chung Hsing University, No. 145 Xingda Rd., South Dist., Taichung City 402, Taiwan; greenjun@gmail.com

2 Crop Improvement Section, Kaohsiung District Agricultural Research and Extension Station, No. 2-6 Dehe Rd., Changzhi Township, Pingtung 908, Taiwan

* Correspondence: jerchiachang@dragon.nchu.edu.tw; Tel.: +886-4-22840340 (ext. 403); Fax: +886-4-22856974

check for updates

Citation: Chu, Y.-C.; Chang, J.-C. Heat Stress Leads to Poor Fruiting Mainly Due to Inferior Pollen Viability and Reduces Shoot Photosystem II Efficiency in "Da Hong" Pitaya. Agronomy 2022, 12, 225. https://doi.org/10.3390/ agronomy12010225

Academic Editors: Muhammad Shahid and Ali Sarkhosh

Received: 22 December 2021

Accepted: 14 January 2022

Published: 17 January 2022

Publisher's Note: MDPI stays neutral with regard to jurisdictional claims in published maps and institutional affiliations.

Copyright: (C) 2022 by the authors. Licensee MDPI, Basel, Switzerland. This article is an open access article distributed under the terms and conditions of the Creative Commons Attribution (CC BY) license (https:// creativecommons.org/licenses/by/ $4.0 /)$.

\begin{abstract}
High summer temperatures (day/night: $40^{\circ} \mathrm{C} / 30^{\circ} \mathrm{C}$ ) are known to cause poor fruiting, reduced fruit/seed weight, and delayed fruit development in the "Da Hong" red-fleshed pitaya (Hylocereus polyrhizus); however, the mechanisms of these effects are unknown. This study examined how high temperature $\left(\mathrm{HT}, 40{ }^{\circ} \mathrm{C} / 30{ }^{\circ} \mathrm{C}\right)$ affects stamen and pistil fertility through pollination combinations and fruit set in "Da Hong" pitaya and evaluated photosystem II (PSII) efficiency in yellowed shoots (cladodes). The in-vitro pollen germination rate was significantly higher at optimal temperature $\left(\mathrm{OT}, 30^{\circ} \mathrm{C} / 20^{\circ} \mathrm{C}\right.$ ) than at $\mathrm{HT}$, which was also associated with a reduced flower length, poor fruit set, small fruit size, and low number of seeds after self-pollination. Meanwhile, fruit set and fruit development were remarkably improved by using the pollens taken from plants grown at OT and moderate temperature $\left(\mathrm{MH}, 35^{\circ} \mathrm{C} / 25^{\circ} \mathrm{C}\right)$ after mutual cross pollination, indicating that the reduction in seed number caused by incomplete fertilization due to inferior pollen viability was the main cause of poor fruiting under HT rather than pistil or photoinhibition, although HT treatment was linked to reductions of PSII efficiency at both the adaxial and abaxial ends of shoots. The results suggested that pollen viability was most affected under HT stress; thus, yielding remarkably reduced fruiting.
\end{abstract}

Keywords: fertility; high-temperature stress; Hylocereus; pistil; photoinhibition; stamen

\section{Introduction}

The pitaya (Hylocereus spp.) is an emerging fruit crop of the Hylocereus genus in the family Cactaceae. It is a climbing cactus that is native to the rainforests of northern South America, Central America, and Mexico [1]. Pitaya has been cultivated economically for $>30$ years, and it is currently a global economic fruit crop primarily cultivated in Southeast Asian countries, including Vietnam, Taiwan, Indonesia, Malaysia, and China's Guangxi and Hainan provinces [2,3]. In addition, it is also cultivated at a small scale in Israel, Nicaragua, Colombia, and Mexico. In recent years, with the northward shift of production locations, some subtropical regions with higher latitudes, including Guizhou in China and Kagoshima, Okinawa, and Fukuoka in Japan, have also started cultivating red-fleshed pitaya $[3,4]$.

The optimal day/night reproductive temperature of pitaya (H. undatus) is $30{ }^{\circ} \mathrm{C} /$ $20{ }^{\circ} \mathrm{C}$ [5]. Temperature stress is detrimental to shoot (cladode) development, flower bud formation, and fruit set, leading to reduced production [5-7]. Although pitaya is widely distributed in its area of production, it is less tolerant to temperature stress than other cactus crops, potentially owing to its indigeneity to rainforest environments [5,8,9]. In Guangxi and Guizhou in China, where winter temperatures reach $0{ }^{\circ} \mathrm{C}$, chilling injury may occur in shoots; thus, only spring sprouts can be cultivated for autumn fruit production [3]. Under 
times of prolonged daylight in winter, warm temperatures $\left(32^{\circ} \mathrm{C} / 22^{\circ} \mathrm{C}\right)$ promote flowering in the early spring or in the production period [10], whereas high temperature (HT) reduces flowering batches and flower production [5,8]. In Israel, high summer temperatures of up to $38^{\circ} \mathrm{C}$ result in the production of $3-4$ waves of flowers (a plant flowers $3-4$ times during the reproductive period), and in some areas of extreme heat $\left(44-46^{\circ} \mathrm{C}\right)$, only one wave of flowers can be produced, in September, resulting in significantly reduced production [5].

"Da Hong" is a major variety of red-fleshed pitaya (H. polyrhizus) cultivated in Taiwan and Southeast Asia with its self-compatibility, large fruit, high yield, and good flavor [6, 11-13]. Although its flowering waves are unaffected by high summer temperatures [7], an increase in the proportion of small fruits $(<150 \mathrm{~g})$ under high summer temperatures $\left(>35^{\circ} \mathrm{C} / 25^{\circ} \mathrm{C}\right)$ is often observed in open fields or netting facilities [6,7].

Chu and Chang [6] confirmed that the fruit set of red-fleshed pitaya is affected by HT, resulting in the occurrence of small fruit size, by transferring plants into phytotrons and subjecting them to short-term HT treatment $\left(40^{\circ} \mathrm{C} / 30^{\circ} \mathrm{C}\right)$. Compared with the findings at $30{ }^{\circ} \mathrm{C} / 20^{\circ} \mathrm{C}$, HT shortened the time to flower development, delayed flower opening and closing, reduced flower length, caused severe fruit drop 1 week after flowering, delayed the development of few fruit sets, and resulted in a seed weight of $<1 \mathrm{~g}$. In addition, although the shoots maintain a higher level of yellowing under high temperatures, the dry matter weight does not decrease, indicating that shoot yellowing under HT does not obstruct fruit set [6]. The optimum temperature (OT) for in-vitro pollen germination in the red-fleshed pitaya "DR3" and white-flesh pitaya (H. undatus) "Vietnam" is $25^{\circ} \mathrm{C}$ [14], and it is speculated that HT may have reduced pollen viability and caused poor fertilization, resulting in less fruiting because of poor fertilization [6]. However, it remains unclear whether HT stress during flower development obstructs floral organ fertility.

During the peak of summer (June-August) in Taiwan, the day and night temperatures are close to $35{ }^{\circ} \mathrm{C}$ and $25^{\circ} \mathrm{C}$, respectively [15]. Under this environment of high light intensity and elevated temperature, the sun-exposed shoots at the adaxial end often burn and exhibit yellowing, and the yellowed shoots naturally re-green in autumn (October) when the temperature decreases [15]. During HT, a 50\% sunshade net placed above the canopy can lower the temperature and reduce the yellowing of shoots [15-18]. However, compared with the findings in an open field, the yellowing of shoot in plants cultivated in a netting facility is not improved even though the light intensity is reduced, owing to the increase in temperature [15]. The same response has been observed under the HT, the phytotorns in which the shoot at the adaxial end of the plants maintained a higher degree of yellowing after being moved from open-field $\left(35^{\circ} \mathrm{C} / 25^{\circ} \mathrm{C}\right)$ to $\mathrm{HT}\left(40^{\circ} \mathrm{C} / 30^{\circ} \mathrm{C}\right)$ conditions in the phytotrons [6]. Both a slightly elevated temperature $\left(35^{\circ} \mathrm{C} / 25^{\circ} \mathrm{C}\right)$ and HT $\left(40^{\circ} \mathrm{C} / 30^{\circ} \mathrm{C}\right)$ under bright light lead to shoot yellowing, which does not affect their dry weight [6]; however, the effect of this yellowing on the photosynthetic efficiency of shoot needs to be further investigated.

When a healthy plant is exposed to stress, electron transport in the photosynthetic system is inhibited, causing chlorophyll fluorescence to rapidly decline. Therefore, changes in chlorophyll fluorescence reflect the photochemical efficiency, and these changes are often used to document the extent of damage to the photosystem caused by stress [19]. The measurement of the maximum photochemical efficiency (Fv/Fm) of photosystem II (PSII) under dark-adapted conditions can be used as an indicator of temperature stress, light stress, and water stress [19]. In several tropical fruit trees, such as pineapple, sugar apple, guava, and papaya trees, chlorophyll fluorescence can be used as an indicator of temperature stress [20-22], but studies on red-fleshed pitaya are rare.

This study aims to extend the results of a previous study on HT-induced effect of suppressing fruiting in "Da Hong" red-fleshed pitaya [6], which used potted plants with open-field cultivation as the study material and then transferred them to phytotrons simulating day/night temperatures of $40^{\circ} \mathrm{C} / 30^{\circ} \mathrm{C}, 35^{\circ} \mathrm{C} / 25^{\circ} \mathrm{C}$, and $30^{\circ} \mathrm{C} / 20^{\circ} \mathrm{C}$, respectively. Through examinations of in-vitro pollen viability and self-pollination or mutual cross combinations under three temperature regimes, the effects of high-temperature stress on stamen 
and pistil fertility and fruit set in "Da Hong" red-fleshed pitaya have been investigated to understand the main causes of poor fruit set under HT. In addition, we also investigated the re-greening of shoots with different degrees of yellowing after treatments, particularly the sun-exposed side of triangular fleshy shoots, and assessed their PSII efficiency after treatment to evaluate the effect of short-term HT stress on the photochemical efficiency of photosynthesis to further understand the physiology of photosynthesis.

\section{Materials and Methods}

\subsection{Plant Materials and Pre-Treatments}

The red-fleshed pitaya "Da Hong," which is sensitive to HT, was selected as the plant material, and the study was performed in the Kaohsiung District Agricultural Research and Extension Station (KDARES), Changzhi Township, Pingtung, southern Taiwan $\left(22^{\circ} 41^{\prime} \mathrm{N}\right.$, $120^{\circ} 31^{\prime}$ E) using 2-3-year-old plants, which were planted in cutting pairs in 15-L pots supported by bamboo poles. The plants were well irrigated, and a soluble fertilizer $(\mathrm{N}: \mathrm{P}: \mathrm{K}=15: 15: 15)$ was added to the irrigation water once a week to maintain good plant development. Considering the space limitation of the phytotron $(3.8 \mathrm{~m} \times 2.4 \mathrm{~m})$, five pots of plants were used in each treatment, and pots of uniform growth potential, including a total of 10-12 mature fruiting shoots in each pot, were selected.

To avoid overload in plants caused by fruiting, the flower buds that emerged before the beginning of the study were removed. The number of flowers left in each pot was adjusted to 5-6 flowers during the study, and the ratio of shoots to fruits was adjusted to 2:1. The study was conducted from July to September in 2017. Owing to the high average temperature $\left(28.7^{\circ} \mathrm{C}\right)$ and high light intensity from May to June, the sun-exposed shoots of the experimented plants displayed some yellowing before the experiment.

Temperature treatments were simulated as $\mathrm{HT}\left(40^{\circ} \mathrm{C} / 30^{\circ} \mathrm{C}\right)$, moderately high temperature $\left(\mathrm{MH}, 35^{\circ} \mathrm{C} / 25^{\circ} \mathrm{C}\right.$ ), and $\mathrm{OT}$ (served as control, $30^{\circ} \mathrm{C} / 20^{\circ} \mathrm{C}$ ) (temperature fluctuation of $\pm 1{ }^{\circ} \mathrm{C}$ permitted for each condition). Potted plants initially grown in the field were transferred into the phytotrons at KDARES within 1-3 days after the emergence of the flower bud and subsequently transferred to OT on 13 July 2017 and to HT and MH on 21 July 2017.

\subsection{Time to Flower Development and Flower Traits}

Nine flowers per treatment were examined for the flower buds that emerged on 16 July or 20 July 2017, and the number of days between floral bud emergence, and flowering was investigated. The full length of the flower and diameter and circumference of the ovary were measured at 12:00 and 17:00 on the day of flowering.

\subsection{In-Itro Pollen Viability Performance of Fresh Pollen}

\subsubsection{Preparation of Pollen Culture Medium}

Pollen culture was performed using the modified Brewbacker and Kwack (BK) medium described by Weiss et al. [23] and Cheng and Weng [14]. The liquid medium contained $100 \mathrm{mg} / \mathrm{L}$ each of $\mathrm{H}_{3} \mathrm{BO}_{3}, \mathrm{Ca}\left(\mathrm{NO}_{3}\right)_{2} \cdot 4 \mathrm{H}_{2} \mathrm{O}, \mathrm{MgSO}_{4} \cdot 7 \mathrm{H}_{2} \mathrm{O}$, and $\mathrm{KNO}_{3}$. The sucrose concentration was $25 \%$, and the $\mathrm{pH}$ was adjusted to $5.5 \pm 0.1$. The solid medium contained $100 \mathrm{mg} / \mathrm{L}$ each of $\mathrm{H}_{3} \mathrm{BO}_{3}, \mathrm{Ca}\left(\mathrm{NO}_{3}\right)_{2} \cdot 4 \mathrm{H}_{2} \mathrm{O}, \mathrm{MgSO}_{4} \cdot 7 \mathrm{H}_{2} \mathrm{O}$, and $\mathrm{KNO}_{3}$, as well as $1 \%$ agar and $20 \%$ sucrose. Its $\mathrm{pH}$ was adjusted to $5.5 \pm 0.1$, and the medium was sterilized at $121^{\circ} \mathrm{C}$ and $1.2 \mathrm{~kg} / \mathrm{cm}^{2}$ for $20 \mathrm{~min}$. It was then poured into Petri dishes and refrigerated at $4{ }^{\circ} \mathrm{C}$ for use.

\subsubsection{Pollen Culture and Observation}

Fresh pollen was collected from the flowers that opened on the same day, and six flowers were collected for each treatment as replicates. The whole flowers were picked at 20:00 on the day of flowering. Ten anthers were randomly obtained from each flower and placed in a 1.5-mL micro centrifuge tube. After adding the liquid medium, the pollen and liquid medium were mixed well by vortexing the microcentrifuge tubes for $10 \mathrm{~s}$ on a 
touch basis. After the anthers were removed, $1 \mathrm{~mL}$ of liquid medium containing pollen was extracted with a dropper and placed on the solid medium. After $24 \mathrm{~h}$ of incubation, pollen germination was observed with an optical microscope (Eclipse 50i, Nikon, Japan). Three hundred pollen grains were examined in each replicate, and pollen tubes longer than twice the length of the pollen were considered as viable pollen.

\subsection{Investigation of Artificial Pollination Combinations, Fruit Set and Fruit Characteristics}

For the experimental plants that flowered from 30 July to 6 August 2017, the pollination of pollen and pistil under three temperature treatments was performed using self- or mutual cross pollinations by hand, including the following nine combinations: OT self-pollination,

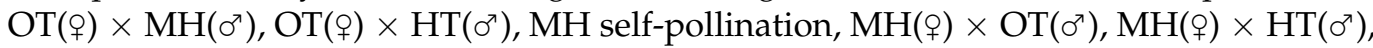
HT self-pollination, $\mathrm{HT}($ ( $) \times \mathrm{OT}\left(\sigma^{7}\right)$, and $\mathrm{HT}($ ( $) \times \mathrm{MH}\left(\sigma^{7}\right)$.

Each combination was pollinated using one-to-six flowers. Excluding the three selfpollination combinations, the maternal stigma was separated from the stamens before 13:00 on the day of flowering. The stigma was then covered with a paper bag to avoid self-pollination. Pollination was performed at 20:00-21:00 at night, and fresh pollen was collected on the same day of flowering. The stigma was brushed with an ink brush to make sure it was evenly covered with pollen for sufficient pollination before covering it with a paper bag, and the paper bags were removed 3 days after flowering. Fruit set was observed 1 week after flowering.

The fruit characteristics of each pollination combination were investigated at approximately 38 days after fruit development with a ripeness code of 819 [13], including individual fruit weight, fruit transversal diameter, fruit longitudinal diameter, fruit flesh weight, fruit peel weight, edible rate, fruit peel thickness, total soluble solid content (TSSC) in the core of the fruit, and seed weight. The color difference between the sun-exposed and shaded sides of the fruit equator was investigated using a color spectrometer (ColorLite sph860; Katlenburg-Lindau, Germany), and the $a^{*}$ value was used to represent the degree of color change of the fruit.

\subsection{Greening of Shoots and Chlorophyll Fluorescence}

2.5.1. Labeling of the Investigated Parts

The plants were divided into the adaxial (the sun-exposed canopy) and abaxial ends (the parts where shoots hang down). As pitaya has a triangular fleshy shoot with the other side facing the sun, 1-3 parts of each treated plant with a similar degree of yellowing as the sun-exposed side were marked (Figure 1) for investigation before and during the experiment. The data of the marked parts on the single plant were averaged as the data of the single plant. Therefore, five replicates of data were included for the statistical analysis of each treatment, and the degree of yellowing of the shoots before and after the experiment was recorded by capturing photographs.

\subsubsection{Investigation of the Re-Greening of Yellowed Shoots}

The shoot color at the adaxial and abaxial ends was measured using a color spectrometer (ColorLite sph860, Katlenburg-Lindau, Germany) weekly before and during the experiment period. The $b^{*}$ value was used to indicate the yellowing or re-greening of the shoots.

\subsubsection{Chlorophyll Fluorescence Performance of Shoots}

$\mathrm{Fv} / \mathrm{Fm}$ of PSII was measured weekly using a pulse amplitude-modulated fluorimeter (Mini-Pam, WALZ. Effeltrich, Germany) before and after the experiment to estimate the degree of photoinhibition in the plants during the study. As it was difficult to dark-adapt the shoots of red-fleshed pitaya with leaf clips, measurements were performed at 20:0021:00 instead of at dark. Fv/Fm of PSII was calculated by measuring Fo and Fm using measuring the light and saturating pulse [24]. 


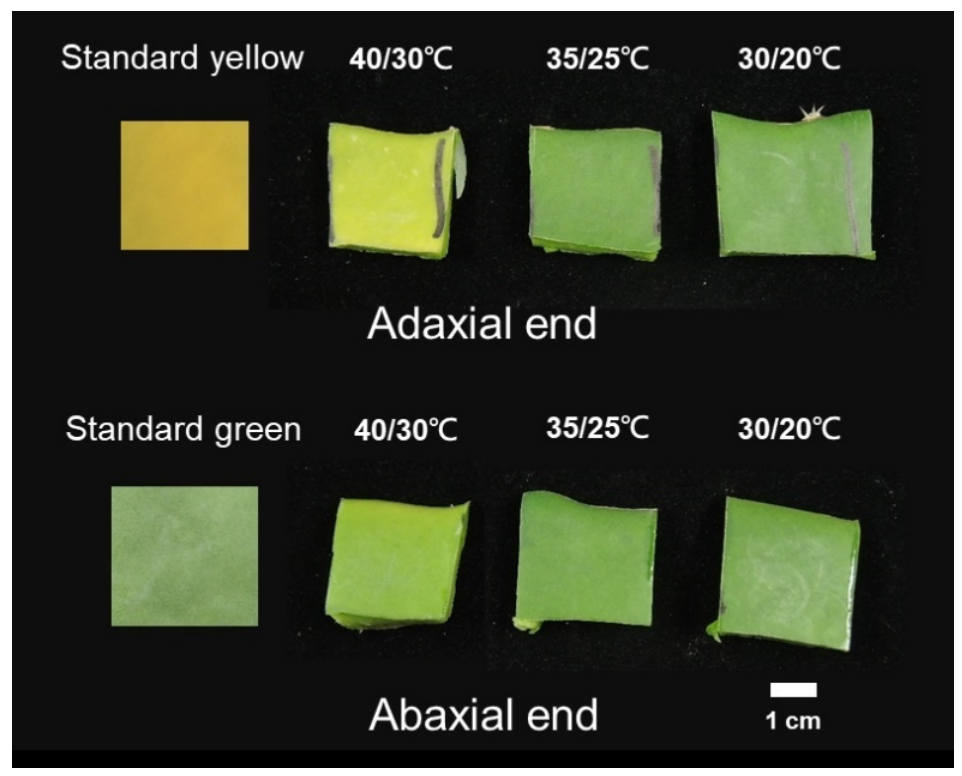

Figure 1. Shoot re-greening on the adaxial and abaxial ends of shoots in "Da Hong" pitaya at the end of the experiment under optimum temperature as control (OT, $\left.30^{\circ} \mathrm{C} / 20^{\circ} \mathrm{C}\right)$, moderately high temperature $\left(\mathrm{MH}, 35^{\circ} \mathrm{C} / 25^{\circ} \mathrm{C}\right)$, and high temperature $\left(\mathrm{HT}, 40^{\circ} \mathrm{C} / 30^{\circ} \mathrm{C}\right.$ ) treatments in 2017 . Standard yellow and standard green were the shoot colors on the adaxial and abaxial ends, respectively, in all three groups before the experiments.

\subsection{Experimental Design and Statistical Analysis}

The data were analyzed using SigmaPlot 14 software (Systat Software, Inc., San Jose, CA, USA), and graphs were plotted. One-way analysis of variance was used for the test data, and the least significant difference (LSD) was used to analyze whether the difference in a pairwise comparison of two treatments were significant. $p<0.05$ indicated a statistically significant difference.

\section{Results}

3.1. Effect of Temperature on the Time to Flower Development, Floral Characteristics, and In-Vitro Pollen Viability

With increasing temperature, the time from flower bud emergence to opening became significantly shorter. Buds subjected to HT and MH bloomed 5-7 days earlier than those subjected to OT (Table 1). Concerning the floral characteristics observed at 12:00 on the day of flowering, both OT and MH led to longer flower length and ovary perimeter than HT, whereas $\mathrm{MH}$ resulted in a longer ovary perimeter than OT and HT. The ovary perimeter under OT continued to increase, and until 17:00 on the day of flowering, there was no significant difference between the ovary perimeter under OT and $\mathrm{MH}$.

Table 1. Comparison of flower characteristics and pollen viability at bloom day in "Da Hong" pitaya.

\begin{tabular}{|c|c|c|c|c|c|c|c|c|}
\hline \multirow[b]{2}{*}{ Treatment $^{1}$} & \multirow{2}{*}{$\begin{array}{l}\text { Floral Bud } \\
\text { Development } \\
\text { Duration } \\
\text { (Days) }\end{array}$} & \multicolumn{3}{|c|}{$12: 00$} & \multicolumn{3}{|c|}{$17: 00$} & \multirow{2}{*}{$\begin{array}{c}\text { In-Vitro } \\
\text { Pollen } \\
\text { Viability } \\
(\%)\end{array}$} \\
\hline & & $\begin{array}{c}\text { Ovary } \\
\text { Diameter } \\
(\mathrm{cm})\end{array}$ & $\begin{array}{c}\text { Flower } \\
\text { Length } \\
\text { (cm) }\end{array}$ & $\begin{array}{c}\text { Ovary } \\
\text { Perimeter } \\
\text { (cm) }\end{array}$ & $\begin{array}{c}\text { Ovary } \\
\text { Diameter } \\
(\mathrm{cm})\end{array}$ & $\begin{array}{c}\text { Flower } \\
\text { Length } \\
(\mathrm{cm})\end{array}$ & $\begin{array}{c}\text { Ovary } \\
\text { Perimeter } \\
(\mathrm{cm})\end{array}$ & \\
\hline HT & $14 c^{2}$ & $3.8 \mathrm{~b}$ & $31.5 \mathrm{~b}$ & $13.9 \mathrm{~b}$ & $3.9 \mathrm{~b}$ & $32.6 \mathrm{~b}$ & $13.2 \mathrm{~b}$ & $0.6 \mathrm{c}$ \\
\hline $\mathrm{MH}$ & $16 \mathrm{~b}$ & $4.3 \mathrm{a}$ & $35.7 \mathrm{a}$ & $14.5 \mathrm{a}$ & $4.3 \mathrm{a}$ & $37.7 \mathrm{a}$ & $14.6 \mathrm{a}$ & $8.9 \mathrm{~b}$ \\
\hline OT & $21 \mathrm{a}$ & $4.2 \mathrm{a}^{2}$ & $36.0 \mathrm{a}$ & $13.0 \mathrm{c}$ & $4.2 \mathrm{a}$ & $37.3 \mathrm{a}$ & $14.3 \mathrm{a}$ & $65.1 \mathrm{a}$ \\
\hline
\end{tabular}

${ }^{1}$ Treatment: HT—high temperature, air day/night temperature of $40{ }^{\circ} \mathrm{C} / 30^{\circ} \mathrm{C} ; \mathrm{MH}$-moderately high temperature, air day/night temperature of $35^{\circ} \mathrm{C} / 25^{\circ} \mathrm{C}$; OT—control, air day/night temperature of $30^{\circ} \mathrm{C} / 20^{\circ} \mathrm{C} .{ }^{2}$ Means followed by different letters within the same column are significantly different by the least significant difference test at $p<0.05$ (flower characteristics, $n=9$; pollen viability, $n=6$ ). 
The results of the in-vitro pollen germination experiment for in-vitro pollen viability demonstrated that the percentage of pollen viability was $65.1 \%, 8.9 \%$, and $0.6 \%$ under OT, $\mathrm{MH}$, and HT, respectively (Table 1).

\subsection{Investigation of the Artificial Pollination Combinations, Fruit Set and Fruit Characteristics}

Among the nine pollination combinations, the fruit set rate under HT self-pollination was only $16.7 \%$, and the remaining eight combinations produced $100 \%$ fruit set (Table 2), suggesting that pollinating pollen with higher viability under HT restore fruit set, and pollinating less viable HT pollen with stigmas under $\mathrm{MH}$ and OT does not reduce fruit set.

Table 2. Comparison of fruit characteristics, including fruit weight, seed weight, longitudinal diameter, transversal diameter, and peel thick from self-pollination or mutual cross combinations by $\mathrm{HT}, \mathrm{MH}$, and OT treatments in “Da Hong" pitaya at harvest in 2017.

\begin{tabular}{|c|c|c|c|c|c|c|c|c|}
\hline \multicolumn{2}{|c|}{ Temperature Treatment $^{1}$} & \multirow[b]{2}{*}{$\begin{array}{c}\text { Fruit Set }{ }^{3} \\
(\%)\end{array}$} & \multirow[b]{2}{*}{$\begin{array}{c}\text { Fruit } \\
\text { Weight } \\
\text { (g) }\end{array}$} & \multirow[b]{2}{*}{$\begin{array}{c}\text { Seed } \\
\text { Weight } \\
\text { (g) }\end{array}$} & \multirow[b]{2}{*}{$\begin{array}{l}\text { Longitudinal } \\
\text { Diameter } \\
\text { (cm) }\end{array}$} & \multirow[b]{2}{*}{$\begin{array}{c}\text { Transversal } \\
\text { Diameter } \\
\text { (cm) }\end{array}$} & \multicolumn{2}{|c|}{ Peel Thickness (mm) } \\
\hline Pistil & $\begin{array}{l}\text { Pollen } \\
\text { Source }\end{array}$ & & & & & & $\begin{array}{c}\text { Sun- } \\
\text { Exposed } \\
\text { Side }\end{array}$ & $\begin{array}{c}\text { Shaded } \\
\text { Side }\end{array}$ \\
\hline HT & $\mathrm{HT}$ & 16.7 & $72.1 \mathrm{e}^{2}$ & $0.4 \mathrm{~g}$ & $7.9 \mathrm{e}$ & $4.2 \mathrm{e}$ & $5.5 \mathrm{a}$ & $3.5 \mathrm{a}$ \\
\hline HT & $\mathrm{MH}$ & 100 & 180.0 de & $3.0 \mathrm{f}$ & $9.1 \mathrm{de}$ & $6.1 \mathrm{~d}$ & $3.1 \mathrm{~b}$ & $2.7 \mathrm{abc}$ \\
\hline HT & OT & 100 & $252.2 \mathrm{~cd}$ & 3.5 ef & $9.7 \mathrm{~d}$ & $6.7 \mathrm{~d}$ & $3.4 \mathrm{~b}$ & $3.1 \mathrm{a}$ \\
\hline $\mathrm{MH}$ & HT & 100 & $264.8 \mathrm{~cd}$ & $4.6 \mathrm{de}$ & $10.8 \mathrm{c}$ & $6.9 \mathrm{~cd}$ & $2.8 \mathrm{~b}$ & $2.5 \mathrm{bcd}$ \\
\hline $\mathrm{MH}$ & $\mathrm{MH}$ & 100 & $391.8 \mathrm{~b}$ & $6.7 \mathrm{bc}$ & $11.9 \mathrm{ab}$ & $8.3 \mathrm{~b}$ & $2.7 \mathrm{~b}$ & $2.5 \mathrm{bcd}$ \\
\hline $\mathrm{MH}$ & OT & 100 & $474.0 \mathrm{~b}$ & $7.5 \mathrm{~b}$ & $12.3 \mathrm{ab}$ & $8.7 \mathrm{~b}$ & $2.8 \mathrm{~b}$ & $3.0 \mathrm{ab}$ \\
\hline OT & HT & 100 & $345.4 \mathrm{bc}$ & $5.7 \mathrm{~cd}$ & $11.5 \mathrm{abc}$ & $7.9 \mathrm{bc}$ & $2.8 \mathrm{~b}$ & $2.3 \mathrm{~cd}$ \\
\hline OT & $\mathrm{MH}$ & 100 & $758.1 \mathrm{a}$ & $10.0 \mathrm{a}$ & $13.2 \mathrm{a}$ & $10.5 \mathrm{a}$ & $3.5 \mathrm{~b}$ & $2.5 \mathrm{abcd}$ \\
\hline OT & OT & 100 & $431.9 \mathrm{~b}$ & $6.3 \mathrm{bc}$ & $11.3 \mathrm{bc}$ & $8.6 \mathrm{~b}$ & $2.6 \mathrm{~b}$ & $2.3 \mathrm{~d}$ \\
\hline
\end{tabular}

${ }^{1}$ Treatment: HT-high temperature, air day/night temperature of $40^{\circ} \mathrm{C} / 30^{\circ} \mathrm{C} ; \mathrm{MH}$-moderately high temperature, air day/night temperature of $35^{\circ} \mathrm{C} / 25^{\circ} \mathrm{C}$; OT—control, air day/night temperature of $30{ }^{\circ} \mathrm{C} / 20^{\circ} \mathrm{C} .{ }^{2}$ Means followed by different letters within the same column are significantly different by the least significant difference test at $p<0.05 .{ }^{3}$ There were between one and six fruits for each treatment.

Compared with the results under OT and $\mathrm{MH}$, fruit development was poorer under HT, as HT self-pollination fruits had an individual fruit weight of $<100 \mathrm{~g}$, a seed weight of only $0.4 \mathrm{~g}$ (Table 2), thicker fruit peel thickness on the sun-exposed side (Table 2), the lowest edible rate of $37.2 \%$ (Table 3), poor performance in terms of the color change of the fruit peel (Figure 2, Table 4), and a lower $\mathrm{a}^{*}$ value for both the sun-exposed and shaded sides of fruit peels than those subjected to the other combinations were observed. Pollination under HT with $\mathrm{MH}$ and OT pollen increased the individual fruit weight to 180 and $252.2 \mathrm{~g}$, respectively and increased the seed weight to 3 and $3.5 \mathrm{~g}$ (Table 2), respectively, despite the fruit/seed weight not being completely improved relative to those of OT (control). Moreover, the flesh weight was higher than that for HT self-pollination, leading to increased edibility rates of approximately 61.1 and $62.7 \%$, respectively (Table 3 ).

Table 3. Comparison of fruit characteristics, including flesh weight, peel weight, edible part, and total soluble solid content from self-pollination or mutual cross combinations by HT, MH, and OT treatments in "Da Hong" pitaya at harvest in 2017.

\begin{tabular}{|c|c|c|c|c|c|}
\hline \multicolumn{2}{|c|}{ Temperature Treatment ${ }^{1}$} & \multirow{2}{*}{$\begin{array}{c}\text { Flesh Weight } \\
\text { (g) }\end{array}$} & \multirow{2}{*}{$\begin{array}{l}\text { Peel Weight } \\
\text { (g) }\end{array}$} & \multirow{2}{*}{$\begin{array}{c}\text { Edible Part } \\
\text { (\%) }\end{array}$} & \multirow{2}{*}{$\begin{array}{l}\text { Total Soluble Solid Conten } \\
\text { ( }{ }^{\circ} \text { brix) }\end{array}$} \\
\hline Pistil & Pollen Source & & & & \\
\hline HT & HT & $26.8 \mathrm{f}^{2}$ & $45.3 \mathrm{~d}$ & $37.2 \mathrm{~d}$ & $15.8 \mathrm{c}$ \\
\hline HT & $\mathrm{MH}$ & $110.7 \mathrm{f}$ & $70.0 \mathrm{~cd}$ & $61.1 \mathrm{c}$ & $17.8 \mathrm{bc}$ \\
\hline HT & OT & 160.0 ef & $92.2 \mathrm{bc}$ & $62.7 c$ & $18.6 \mathrm{abc}$ \\
\hline
\end{tabular}


Table 3. Cont.

\begin{tabular}{|c|c|c|c|c|c|}
\hline \multicolumn{2}{|c|}{ Temperature Treatment $^{1}$} & \multirow{2}{*}{$\begin{array}{l}\text { Flesh Weight } \\
\text { (g) }\end{array}$} & \multirow{2}{*}{$\begin{array}{l}\text { Peel Weight } \\
\text { (g) }\end{array}$} & \multirow{2}{*}{$\begin{array}{c}\text { Edible Part } \\
(\%)\end{array}$} & \multirow{2}{*}{$\begin{array}{l}\text { Total Soluble Solid Content } \\
\left.\text { ( }{ }^{\circ} \text { brix }\right)\end{array}$} \\
\hline Pistil & Pollen Source & & & & \\
\hline $\mathrm{MH}$ & HT & 198.0 de & $66.8 \mathrm{~cd}$ & $74.7 \mathrm{a}$ & $18.8 \mathrm{abc}$ \\
\hline $\mathrm{MH}$ & $\mathrm{MH}$ & $295.7 \mathrm{bc}$ & $96.0 \mathrm{~b}$ & $75.3 \mathrm{ab}$ & $20.0 \mathrm{a}$ \\
\hline $\mathrm{MH}$ & OT & $368.4 \mathrm{~b}$ & $105.7 \mathrm{~b}$ & $77.9 \mathrm{ab}$ & $19.9 \mathrm{ab}$ \\
\hline OT & HT & $256.9 \mathrm{~cd}$ & $88.5 \mathrm{bcd}$ & $73.8 \mathrm{~b}$ & $17.8 \mathrm{abc}$ \\
\hline OT & $\mathrm{MH}$ & 594.7 a & $163.4 \mathrm{a}$ & $78.4 \mathrm{ab}$ & $18.8 \mathrm{abc}$ \\
\hline OT & OT & $341.8 \mathrm{bc}$ & $90.1 \mathrm{bc}$ & $79.0 \mathrm{a}$ & $20.0 \mathrm{a}$ \\
\hline
\end{tabular}

${ }^{1}$ Treatment: HT—high temperature, air day/night temperature of $40{ }^{\circ} \mathrm{C} / 30^{\circ} \mathrm{C}$; $\mathrm{MH}$-moderately high temperature, air day/night temperature of $35^{\circ} \mathrm{C} / 25^{\circ} \mathrm{C}$; OT—control, air day/night temperature of $30^{\circ} \mathrm{C} / 20^{\circ} \mathrm{C} .{ }^{2}$ Means followed by different letters within the same column are significantly different by the least significant difference test at $p<0.05 .{ }^{3}$ One to six fruits for each treatment.

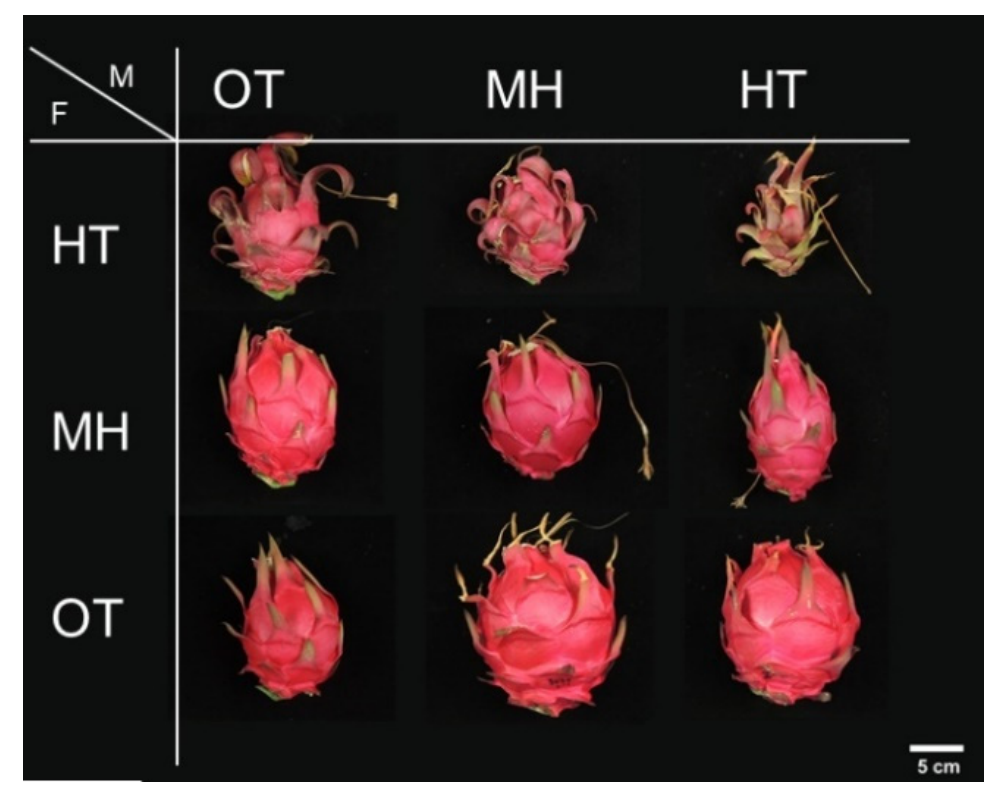

Figure 2. Fruit characteristics after self-pollination or mutual cross combinations by control (OT, $30{ }^{\circ} \mathrm{C} / 20{ }^{\circ} \mathrm{C}$ ), moderately high temperature $\left(\mathrm{MH}, 35^{\circ} \mathrm{C} / 25^{\circ} \mathrm{C}\right.$ ), and high temperature (HT, $\left.40{ }^{\circ} \mathrm{C} / 30^{\circ} \mathrm{C}\right)$ treatments in “Da Hong" pitaya at harvest in $2017(\mathrm{M}$, pollen source; F, pistil).

Table 4. Comparison of peel color from self-pollination or mutual cross combinations by $\mathrm{HT}, \mathrm{MH}$, and OT treatments in "Da Hong" pitaya at harvest in 2017.

\begin{tabular}{|c|c|c|c|c|c|c|c|}
\hline \multicolumn{2}{|c|}{ Temperature Treatment ${ }^{1}$} & \multicolumn{3}{|c|}{ Sun-Exposed Side } & \multicolumn{3}{|c|}{ Shaded Side } \\
\hline Pistil & Pollen Source & $\mathbf{L}^{3}$ & $a^{*}$ & $\mathbf{b}^{*}$ & $\mathbf{L}$ & $a^{*}$ & $\mathbf{b}^{*}$ \\
\hline HT & HT & $48.3 \mathrm{a}^{2}$ & $8.2 \mathrm{~b}$ & $7.3 \mathrm{a}$ & $46.0 \mathrm{a}$ & $11.0 \mathrm{~b}$ & $6.4 \mathrm{a}$ \\
\hline HT & $\mathrm{MH}$ & $39.7 \mathrm{~b}$ & $31.4 \mathrm{a}$ & $-1.3 \mathrm{~cd}$ & $42.5 \mathrm{~b}$ & $39.5 \mathrm{a}$ & $0.7 \mathrm{bc}$ \\
\hline HT & OT & $41.6 \mathrm{~b}$ & $28.4 \mathrm{a}$ & $0.4 \mathrm{bc}$ & $42.8 \mathrm{~b}$ & $36.3 \mathrm{a}$ & $-1.1 \mathrm{~d}$ \\
\hline $\mathrm{MH}$ & HT & $42.0 \mathrm{~b}$ & $35.7 \mathrm{a}$ & $-1.7 \mathrm{~d}$ & $39.7 \mathrm{~cd}$ & $37.9 \mathrm{a}$ & $-1.4 \mathrm{~d}$ \\
\hline $\mathrm{MH}$ & $\mathrm{MH}$ & $41.7 \mathrm{~b}$ & $35.3 \mathrm{a}$ & $-0.9 \mathrm{bcd}$ & $39.0 \mathrm{~d}$ & $37.3 \mathrm{a}$ & $-0.3 \mathrm{~cd}$ \\
\hline $\mathrm{MH}$ & OT & $37.8 \mathrm{~b}$ & $37.6 \mathrm{a}$ & $-0.8 \mathrm{bcd}$ & $38.0 \mathrm{~d}$ & $39.1 \mathrm{a}$ & $-0.3 \mathrm{~cd}$ \\
\hline OT & HT & $39.4 \mathrm{~b}$ & $33.8 \mathrm{a}$ & $1.1 \mathrm{~b}$ & $41.3 \mathrm{bc}$ & $36.6 \mathrm{a}$ & $1.6 \mathrm{~b}$ \\
\hline OT & $\mathrm{MH}$ & $37.8 \mathrm{~b}$ & $38.6 \mathrm{a}$ & $-1.2 \mathrm{bcd}$ & $38.8 \mathrm{~d}$ & $39.8 \mathrm{a}$ & $-2.5 \mathrm{~d}$ \\
\hline OT & OT & $41.1 \mathrm{~b}$ & $34.7 \mathrm{a}$ & $0.2 \mathrm{bcd}$ & $39.5 \mathrm{~d}$ & $37.4 \mathrm{a}$ & $0.6 \mathrm{~d}$ \\
\hline
\end{tabular}

${ }^{1}$ Treatment: HT_high temperature, air day/night temperature of $40^{\circ} \mathrm{C} / 30^{\circ} \mathrm{C} ; \mathrm{MH}$-moderately high temperature, air day/night temperature of $35^{\circ} \mathrm{C} / 25^{\circ} \mathrm{C}$; OT—control, air day/night temperature of $30{ }^{\circ} \mathrm{C} / 20^{\circ} \mathrm{C} .{ }^{2}$ Means followed by different letters within the same column are significantly different by the least significant difference test at $p<0.05 .{ }^{3}$ One to six fruits for each treatment. 
The fruit characteristics were similar between MH self-pollination or pollination with OT pollen under $\mathrm{MH}$ treatment, with fruit weights of 391.8 and $474 \mathrm{~g}$, respectively, and seed weights of 6.7 and $7.5 \mathrm{~g}$, respectively (Table 2). There were no significant differences in other fruit characteristics and fruit peel color; however, pollination with HT pollen resulted in reductions of fruit weight and seed weight to 264.8 and $4.6 \mathrm{~g}$, respectively (Table 2). By contrast, there was no significant difference in fruit characteristics between OT self-pollination and pollination with HT pollen under OT treatment, with the individual fruit weights being 431.9 and $345.4 \mathrm{~g}$, respectively, and the seed weights being 6.3 and $5.7 \mathrm{~g}$, respectively. Moreover, no significant difference was found for other fruit characteristics and fruit peel color, and the fruit development of these two combinations was similar to that of MH self-pollination and MH pollination with OT pollen (Table 2). The highest individual fruit weight and seed weight of $758.1 \mathrm{~g}$ and $10 \mathrm{~g}$, respectively, were obtained with the combination of pollination with $\mathrm{MH}$ pollen under OT treatment, but the peel thickness, edibility rate, and TSSC were similar to those of the other combinations (Tables 2 and 3).

Under MH and OT treatments, all the fruits appeared elliptical to nearly circular in shape, whereas the fruit under HT had downward curved bracts with a slightly wrinkled peel surface (Figure 2).

\subsection{Re-Greening of Yellowed Shoots and Performance of Chlorophyll Fluorescence}

A week after the plants were transferred into the phytotrons, the $b^{*}$ values of the adaxial ends of plants grown under the three temperatures were greatly reduced, and significant re-greening occurred, although the effects were more significant under $\mathrm{MH}$ and OT. Re-greening continued slowly for 2-7 weeks after treatment (Figure 3A). The $b^{*}$ value of the abaxial end was lower than that of the adaxial end before the experiment, and no significant yellowing was observed. After 1 week of the experiment, OT induced the most significant re-greening, $\mathrm{MH}$ tended to promote re-greening in the second week after treatment. However, the $b^{*}$ value did not display a decreasing trend for HT treatment, and no re-greening occurred in the abaxial end (Figure 3B).

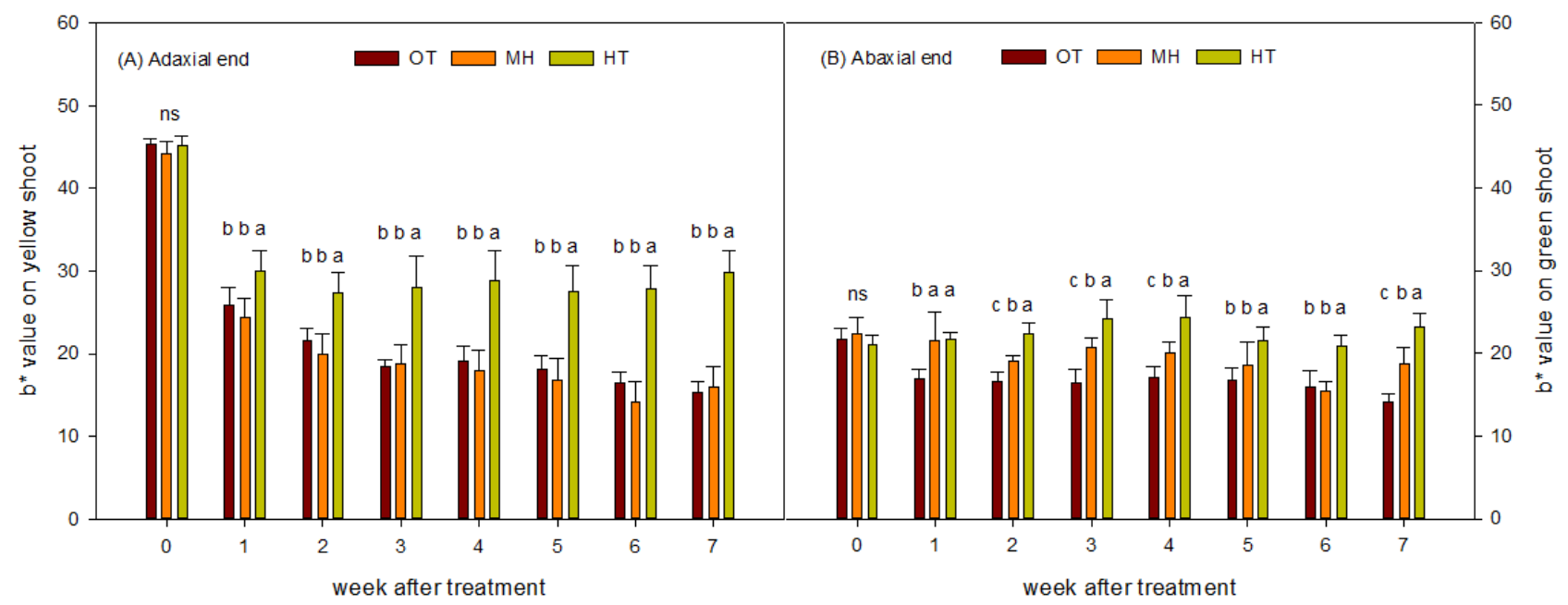

Figure 3. The color change of the shoot on the adaxial (A) and abaxial ends (B) was described as the $b^{*}$ value in "Da Hong" pitaya during control $\left(\mathrm{OT}, 30^{\circ} \mathrm{C} / 20^{\circ} \mathrm{C}\right)$, moderately high temperature $\left(\mathrm{MH}, 35^{\circ} \mathrm{C} / 25^{\circ} \mathrm{C}\right)$ and high temperature $\left(\mathrm{HT}, 40^{\circ} \mathrm{C} / 30^{\circ} \mathrm{C}\right)$ treatments. ns-not significant at the $5 \%$ level. Means followed by different letters within the group bars are significantly different by the least significant difference test at $p<0.05$. Each value represents the mean $\pm \mathrm{SD}$ of five potted plants. Between one and three positions were measured in each potted plant.

The PSII efficiency at the adaxial end was lower than that at the abaxial end before treatment (Figure 4A). At 1 week after treatment, the PSII efficiency at the adaxial end increased for all three treatments. At 2 weeks after treatment, the PSII efficiency in MH and 
OT recovered to above 0.84 , whereas that in HT declined until the end of the experiment (Figure 4A). The PSII efficiency at the abaxial end before treatment was $>0.83$ (Figure $4 \mathrm{~B}$ ), and the PSII efficiency in the MH and OT groups did not change significantly after treatment, with no significant difference noted between the groups. However, the PSII efficiency in the HT group decreased slowly but significantly at $2-4$ weeks after the experiment, and a significant decrease occurred after 5-8 weeks (Figure 4B).

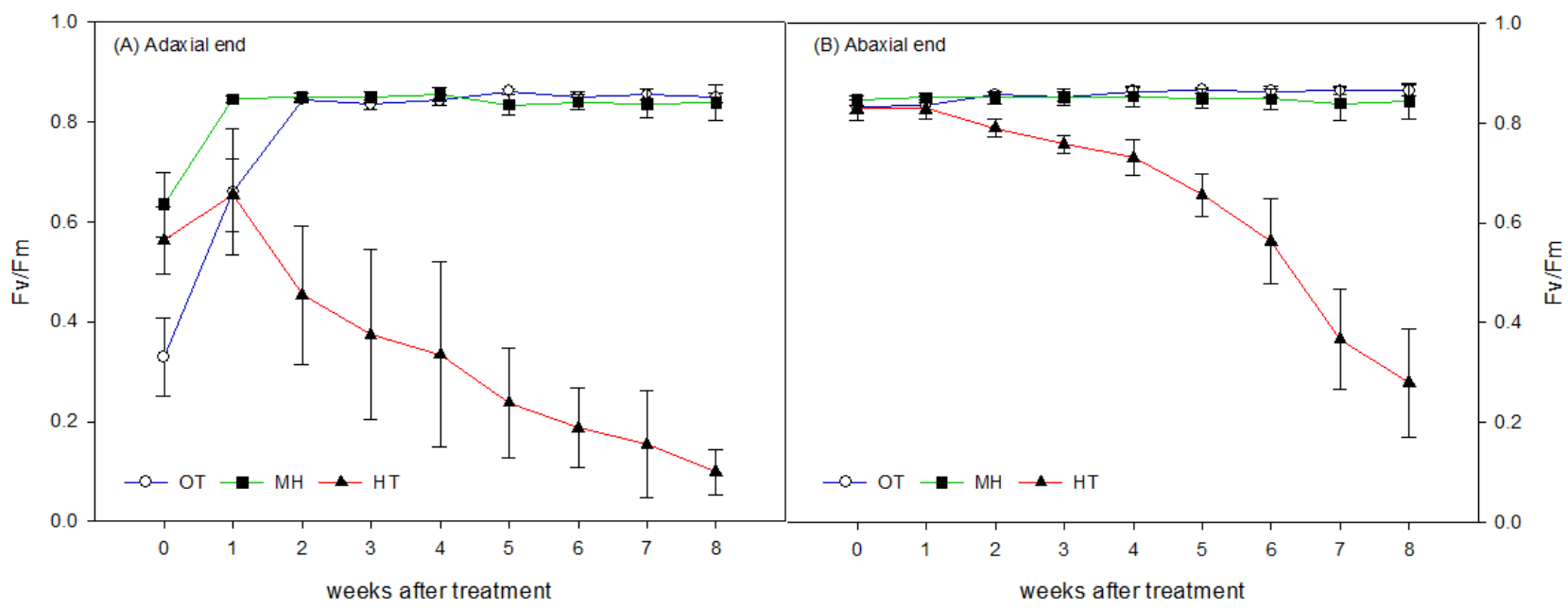

Figure 4. The PSII efficiency (Fv/Fm) on the adaxial (A) and abaxial ends (B) of shoots under control $\left(\mathrm{OT}, 30^{\circ} \mathrm{C} / 20^{\circ} \mathrm{C}\right)$, moderately high temperature $\left(\mathrm{MH}, 35^{\circ} \mathrm{C} / 25^{\circ} \mathrm{C}\right)$, and high temperature $(\mathrm{HT}$, $40{ }^{\circ} \mathrm{C} / 30^{\circ} \mathrm{C}$ ) treatments during the experiment in 2017. Each value represents the mean $\pm \mathrm{SD}$ of five potted plants. Between one and three positions were measured in each potted plant.

\section{Discussion}

The effects of HT stress on flowering and fruit set included delayed or early flowering, dichogamy of pistil and androecium development, defects in floral tissues (e.g., developmental failure of the ovule and ovary, obstructed anther dehiscence), and gamete defects (e.g., reduced pollen viability, poor pollen tube growth), all of which directly affect crop yield and quality [25]. In general, C3 or C4 plants, such as cotton, have increased stomatal conductance at HT, which helps them dissipate heat and reduce leaf temperature [26]. However, the pitaya is a crassulacean acid metabolism (CAM) plant in which the stomata of shoots are closed the during daytime [5], resulting in the inability to dissipate heat during HT stress. When the temperature at noon is over $35^{\circ} \mathrm{C}$, the surface temperature of red-fleshed pitaya shoots can exceed above $50^{\circ} \mathrm{C}$ [7]; thus, HT stress can cause damage in red-fleshed pitaya during the summer season.

In this study, HT treatment $\left(40^{\circ} \mathrm{C} / 30^{\circ} \mathrm{C}\right)$ shortened the time to flower development, and the number of days required for flower development after flower emergence decreased significantly with increasing temperature. This trend was similar to the results of a previous study [6], validating our results. A variety of Oryza sativa subsp. indica, IR64, also exhibits similar performance under HT, in which the proportion of early flowering spikelets is increased when the temperature reaches $36.2{ }^{\circ} \mathrm{C}$ compared with that at $29.2{ }^{\circ} \mathrm{C}$ [27], suggesting that the timing of "Da Hong" flowering can be accelerated when the accumulated temperature is increased by HT treatment.

The flowers of the "Da Hong" continue to develop on the day of flowering. HT reduced flower length, which is consistent with the results of a previous study [6]. Although the flowers under $\mathrm{MH}$ treatment opened 5 days earlier, the flower length, ovary diameter, and ovary perimeter on the day of flowering were not significantly different from those under OT treatment, indicating that $\mathrm{MH}$ accelerated flower development without affecting flower characteristics. 
The in-vitro pollen germination rate was significantly lower under $\mathrm{MH}$ or HT than under OT, confirming that pollen viability during flower development is significantly reduced if the temperature exceeds $35^{\circ} \mathrm{C} / 25^{\circ} \mathrm{C}$ even though $\mathrm{MH}$ did not affect flower characteristics. Wu [28] preliminarily reported that the collection of "Da Hong" pollen on the day of flowering, thus, incubation at $25{ }^{\circ} \mathrm{C}$ resulted in the highest in-vitro germination rate of $61 \%$. When the incubation temperature was $30-40{ }^{\circ} \mathrm{C}$, the in-vitro germination rate decreased, but the pollen viability was approximately $10-22 \%$, which was higher than that under $\mathrm{MH}$ and $\mathrm{HT}$ at current study, indicating that continuous HT treatment during flower development has a greater impact on the floral organ fertility of the red-fleshed pitaya than HT only on the day of flowering, which is similar to the observation in cherimoya [29]. Six days after floral bud emergence in the pitaya, the mother cells of pollen entered meiosis to form microspores and then underwent mitosis, and by 2-3 days before flowering, threecelled pollen grains developed [30]. Müller and Rieu [31] noted that the meiotic and mitotic phases of pollen development are sensitive to HT, which can lead to abnormal chromosome segregation. The tapetum, which supports pollen development, is also affected by HT. Specifically, the tapetum becomes defective under HT, making pollen less fertile [31]. No studies to date have explored the effects of HT on pollen development and fertility in red-fleshed pitaya. However, it can be tentatively concluded that HT treatment during flower development may affect the meiosis of microspore mother cells during the formation of pollen grains. Therefore, this is more likely to reduce pollen fertility than HT only on the day of flowering.

The function of the pistil could be initially assessed by post-pollination fruit set, individual fruit weight, and seed weight. In this study, the results indicated that under HT, the pistil maintains relatively good functioning (Table 2). After pollination with more viable pollen, fertilization success was enhanced, and seed weight was increased to stimulate fruit development. Under MH, even when HT pollen with extremely low viability was pollinated, fruit set remained high, but individual fruit/seed weight was not substantially improved. If self-pollination or pollination with OT pollen was performed, the individual fruit weight could be increased to $>390 \mathrm{~g}$. Additionally, there were no significant differences in fruit set, individual fruit weight, and seed weight between the pollination of HT pollen with $\mathrm{MH}$ and OT stigma; thus, it can be assumed that $\mathrm{MH}$ treatment does not affect the function of the pistil.

The pollen viability of the papaya variety "Wonder Flare" fell to $0 \%$ when the average temperature reached $28.2-30.5^{\circ} \mathrm{C}$ from July to September, but for plants from open-field cultivation and those with more viable pollen (35\%), the fruit set, fruit weight, and number of seeds were increased [32], suggesting that papaya and "Da Hong" pitaya behave similarly under HT, with the function of the pistil being less affected than that of the stamen.

The results of in-vitro pollen germination and pollination combinations at various temperature treatments confirmed the previous hypothesis that HT reduces pollen viability, resulting in poor fertilization and small fruit size in "Da Hong" red-fleshed pitaya [6]. Metz et al. [33] revealed that the in-vitro germination rate of "clone $C$ " red-fleshed pitaya decreased to $<11 \%$ when pollen was stored for 3 months, but when the pollen intensity (pollen amount) was sufficient, the pollen remained able to promote fruit set by artificial pollination. Therefore, although pollen viability was significantly reduced under $\mathrm{MH}$ treatment, the function of the pistil was less affected by HT treatment. In this study, even if pollens with lower viability were used for artificial pollination; however, pollen fully covering the stigma would be sufficient to stimulate normal fruit set and development. Therefore, when pollen viability is reduced by HT or storage conditions, fruit set can be promoted if the sufficient pollination, is provided.

The seed weight of all fruit under the HT condition was similar to that reported by Chu and Chang [6]. However, fruit set and seed weight could be restored for HT pistils pollinated with $\mathrm{MH}$ or OT, indicating that the increase in seed weight (number) both increased the fruit weight and ensured fruit set. In papaya, 70\% of flowers can set fruit and form seedless fruits even without artificial pollination at HT [32]. Tomatoes can activate 
parthenocarpy at HT [34]; however, "Da Hong" pitaya does not undergo parthenocarpy in its natural state; thus, it can be inferred that a certain number of seeds must be produced after pollination for fruit set and normal development to proceed, similar to stone fruit [35].

Our previous study confirmed that HT delays fruit development, results in poor color changes in fruit appearance, and induces the development of sharply downward-curving bracts [6]. Similar characteristics were observed in fruit developed under HT in the present study. The flesh of "Da Hong" pitaya continues to develop after fruit set until harvest, whereas the development of the peel is less significant. As the fruit matures, chlorophyll degradation and betalain formation will cause the peel to gradually change from green to red in color and to become thin because of the reduced water content; thus, the flesh formation rate continues to increase $[17,36,37]$. The coloring of the fruit peel of red-fleshed pitaya is related to the degree of bag shading, in which the $\mathrm{a}^{*}$ value and coloration improve with increases in the degree of shading, whereas HT increases the thickness of the fruit peel and bracts [38]. During the study, the fruit of all treatments were not bagged. However, the poor color change in the fruit peel in the HT self-pollination group was more significant than that for the cross-pollination of HT pistils under $\mathrm{MH}$ and OT pollen treatments, the peel thickness on the sun-exposed side was significantly higher than that of the other treatments, and the edibility rate was lower than that of the other treatments, indicating that the poor fertilization caused by HT resulted in both delayed fruit development and extremely low flesh growth, leading to higher peel thickness and changes in coloration.

According to Zinn et al. [25] and Liu [39], HT affects the flowering and fruiting of plants and damages photosynthetic tissues, thereby inhibiting photosynthesis. HT stress decreases the activity of the oxygen-evolving complex of PSII, which disrupts the structure of the thylakoid membrane, resulting in blocked electron transport. By measuring chlorophyll fluorescence, we could assess Fv / Fm, through which the photosynthetic efficiency of plants subjected to different temperature stresses could be assessed.

Short-term HT stress $\left(45^{\circ} \mathrm{C} / 35^{\circ} \mathrm{C}\right)$ for $7-10$ days in white-fleshed pitaya resulted in reduced PSII activity and net $\mathrm{CO}_{2}$ uptake [24]. After 10 weeks under HT treatment, the daily variation of net $\mathrm{CO}_{2}$ uptake was significantly lower than those under OT and $\mathrm{MH}$, and the yellowing and gangrene of shoots occurred. Prolonged HT stress for 19 weeks resulted in a lower dry plant weight, and gangrene of the shoots was not reversed after lowering the temperature [5]. However, Chu and Chang [6] reported that when entire red-fleshed pitaya plants in pots were placed under HT for 8 weeks, only the sun-exposed shoots at the adaxial end maintained a higher degree of yellowing without a significant reduction in dry matter weight, indicating that short-term HT stress does not affect the carbon supply of shoots.

Before plants were transferred into phytotrons in this study, the adaxial end of potted red-fleshed pitaya plants displayed greater yellowing than the abaxial end. After 1 week of treatment, the $b^{*}$ value of the adaxial end was significantly decreased, indicating that the shoots started to re-green, and the effect was more significant under OT and MH than under HT. These findings are identical to the results of a previous study [6]. After treatment of the abaxial end, only the $b^{*}$ values under OT and MH decreased, and re-greening was observed; however, the degree of re-greening under OT was higher. The average temperature of the HT environment, average low temperature, and average temperature of the open field before the experiment were $34^{\circ} \mathrm{C}, 24.9^{\circ} \mathrm{C}$, and $28.7^{\circ} \mathrm{C}$, respectively, which were close to the temperatures of $\mathrm{MH}$ treatment. The light penetration rate in the phytotrons was reduced by approximately $20-30 \%$. After the plants were moved to the phytotrons, the re-greening performance of the adaxial and abaxial ends of the MH-treated plants suggested that high light intensity is the main cause of shoot yellowing in summer. Under HT, the higher light intensity received at the adaxial end of shoot maintained a higher level of yellowing, indicating that light and HT have a synergistic effect on the yellowing of shoots.

The PSII efficiency of the adaxial end of the plant before treatment was lower than that of the abaxial end, whereas the PSII efficiency of the abaxial end was close to the constant of 0.83 for healthy plants. The adaxial end displayed an upward trend 1 week after treatment, 
indicating that the lower PSII efficiency of the adaxial end before treatment was influenced by high light intensity. In comparison with the re-greening of the shoots, it was assumed that the yellowing of the adaxial end is a temporary phenomenon under high light intensity that does not damage the cells of the fleshy stem.

In this study, we obtained the same results as Chu and Chang [6], who reported the inhibition of shoot yellowing and re-greening on the sun-exposed shoots under HT accompanied by decreasing PSII efficiency, and the response of PSII to HT stress became negative approximately 2 weeks after treatment. The PSII efficiency of the HT sun-exposed adaxial end increased because of shading after a week of treatment but then began to decline in the second week before continuing to decline until the end of the study. The HT abaxial end also displayed a similar trend. Although the yellowing rate of the MT abaxial end shoots was slightly higher than that of the OT shoots, this did not affect the PSII performance. The PSII efficiency under HT can be understood from the fact that the efficiency gradually decreased after 2 weeks under HT and dropped to $<0.6$ after 4 weeks and $<0.4$ after 8 weeks of treatment. However, the plants still did not exhibit gangrene. As the shoots of red-fleshed pitaya are fleshy stems with three sides, the photosynthetic tissues were damaged to different degrees under HT, and only the sun-exposed side exhibited yellowing and photoinhibition [6]. This may explain the reason why short-term HT did not reduce the dry matter weight of shoots as reported by Chu and Chang [6].

The HT-treated plants flowered and completed pollination and fertilization in approximately 2 weeks after treatment, and then the PSII efficiency began to decrease. This indicated that the development and fertility of floral organs are first inhibited under HT, and then the photosynthetic capacity of sun-exposed shoots decreases with increasing HT stress time, confirming that the occurrence of small fruit is mainly caused by HT-induced reductions of pollen fertility. This leads to poor fertilization and fewer seeds, and providing sufficient and viable pollen can increase the number of seeds and fruit weight under HT treatment. Therefore, the short-term reduction of PSII efficiency under HT does not affect fruit development. However, if the duration of HT treatment increases, the shoots would develop continuous and prolonged photoinhibition or even gangrene [15], which would not exclude the reduction of assimilate accumulation and could even affect the subsequent flower bud emergence and fruit set. The effects of long-term HT stress on red-fleshed pitaya flowering and fruit set to be further investigated.

The effects of MH and HT groups on floral development, floral organ fertility, shoot yellowing, and PSII efficiency can be understood from the differences in HT tolerance among organs, such as the reduction of pollen fertility under MH. The PSII efficiency of shoots decreased only when the temperature is increased to $40^{\circ} \mathrm{C} / 30^{\circ} \mathrm{C}$ for 2 weeks. Moreover, the extent to which the function of the pistil or stigma-pollen interaction is affected by HT may be somewhere in between the two, but follow-up study is required for validation.

\section{Conclusions}

The present study confirmed that fruit drop and the obstruction of fruit set and small fruit produced under HT during the period from floral development to fruit maturation of "Da Hong" pitaya is mainly caused by reduced pollen viability, as opposed to reduced PSII efficiency. The flower development is not restricted and the function of the pistil is less affected by HT. Fruit set under HT can be restored by pollinating the viable pollens taken from OT and $\mathrm{MH}$, but the fruit weight is not completely improved.

High light intensity under MH has a greater effect on the efficiency of PSII. If appropriate shading can be applied in the field, the degree of yellowing shoots and photoinhibition are expected to be reduced, thereby maintaining higher photosynthetic efficiency. From the results of different durations of HT treatment, it can be concluded that the reproductive and vegetative organs of red-fleshed pitaya are affected by HT to different degrees during natural production, with pollen viability being most affected, followed by pistil functioning, flower and fruit development and the PSII efficiency of shoot. However, in 
addition to pollen viability, whether reduced compatibility of pollen for the stigma causes poor fertilization should be further investigated.

Additionally, the results of this study can be used to develop production strategies for red-fleshed pitaya during the HT period or as a basis for improving the orchard environment. In the future, attention should be paid to HT during the natural production period in orchard management, and the provision of timely artificial pollination or fieldcooling equipment will help stabilize the production during the HT period.

Author Contributions: Conceptualization, J.-C.C. and Y.-C.C.; methodology, Y.-C.C.; software, Y.C.C.; validation, J.-C.C.; formal analysis, Y.-C.C.; investigation, Y.-C.C.; resources, Y.-C.C.; data curation, Y.-C.C.; writing-original draft preparation, Y.-C.C.; writing-review and editing, J.-C.C.; visualization, J.-C.C.; supervision, J.-C.C.; project administration, J.-C.C.; funding acquisition, J.-C.C. All authors have read and agreed to the published version of the manuscript.

Funding: This research was funded by Ministry of Science and Technology, Taiwan, Republic of China, grant number 109-2313-B-005-021-MY3 (to J.-C.C.).

Data Availability Statement: Data sets analyzed during the current study are available from the current author on reasonable request.

Acknowledgments: We appreciate Yi-Hsuan Hsu and I-Szu Weng for their technical assistance in this study.

Conflicts of Interest: The authors declare no conflict of interest.

\section{References}

1. Mizrahi, Y.; Nerd, A.; Nobel, P.S. Cacti as Crops. In Horticultural Reviews; Jules, J., Ed.; John Wiley \& Sons: New York, NY, USA, 1997; Volume 18, pp. 291-319.

2. Mizrahi, Y. Thirtyone years of research and development in the vine cacti pitaya cultivation in Israel. In Improving Pitaya Production and Marketing, Proceedings of the Workshop on Improving Pitaya Production and Marketing, Kaohsiung, Taiwan, 7-9 September 2015; Jiang, Y.L., Liu, P.C., Huang, P.H., Eds.; Fengshan Tropical Horticultural Experiment Branch: Kaohsiung, Taiwan, 2015; pp. 1-18.

3. Yen, C.R.; Tran, D.H.; Jiang, Y.L. World pitaya production. In Improving Pitaya Production and Marketing, Proceedings of the Workshop on Improving Pitaya Production Technology in Taiwan, Pingtung, Taiwan, 16 April 2014; Liu, P.C., Chiou, K.D., Eds.; Fengshan Tropical Horticultural Experiment Branch: Pingtung, Taiwan, 2015; pp. 19-27.

4. Ohta, S. The Dragon Fruit Industry and Import Situation in Japan. Available online: https://dfnet.fftc.org.tw/Page/ArticleDetail. aspx?ArticleID=fruLnHgwX1Q $\% 3 \mathrm{D} \& \mathrm{PI}=\mathrm{vU} 5 \mathrm{O} \% 2 \mathrm{BMVWGmA} \% 3 \mathrm{D} \& \mathrm{Co}=\mathrm{ztBzV} \% 2 \mathrm{~F} 10 \mathrm{sco} \% 3 \mathrm{D} \& \mathrm{Ca}=\mathrm{nBn} 2 \mathrm{NoFHF} \% 2 \mathrm{FveWcrJt}$ 7\%2F9LI2oreEhheaAG1pWilk58sKi\%2FuQAa\%2BOUE\%2Bm\%2B32EuQ0gart6Q\%2BgRCAARQi\%2FGu2KvrGQ\%3D\%3D\& Ws=ztBzV\%2F10sco\%3D\&Keyword=ztBzV\%2F10sco\%3D (accessed on 13 December 2021).

5. Nobel, P.S.; Dela Barrera, E. High temperatures and net $\mathrm{CO}_{2}$ uptake, growth, and stem damage for the hemiepiphytic cactus Hylocereus undatus. Biotropica 2002, 34, 225-231. [CrossRef]

6. Chu, Y.C.; Chang, J.C. High temperature suppresses fruit/seed set and weight, and cladode regreening in red-fleshed 'Da Hong' pitaya (Hylocereus polyrhizus) under controlled conditions. HortScience 2020, 55, 1259-1264. [CrossRef]

7. Chien, Y.C.; Chang, J.C. Comparison of microclimate and fruit production of red pitaya "Da Hong" in summer and autumn seasons under net house culture. Hortic. NCHU 2018, 43, 1-13.

8. Nerd, A.; Sitrit, Y.; Kaushik, R.A.; Mizrahi, Y. High summer temperatures inhibit flowering in vine pitaya crops (Hylocereus spp.). Sci. Hortic. 2002, 96, 343-350. [CrossRef]

9. Smith, S.D.; Didden-Zopfy, B.; Nobel, P.S. High-temperature responses of North American cacti. Ecology 1984, 65, 643-651. [CrossRef]

10. Chu, Y.C.; Chang, J.C. Regulation of floral bud development and emergence by ambient temperature under a long-day photoperiod in white-fleshed pitaya (Hylocereus undatus). Sci. Hortic. 2020, 271, 109479. [CrossRef]

11. Jiang, Y.L.; Yang, W.J. Development of integrated crop management systems for pitaya in Taiwan. In Improving Pitaya Production and Marketing, Proceedings of the Workshop on Improving Pitaya Production and Marketing, Kaohsiung, Taiwan, 7-9 September 2015; Jiang, Y.L., Liu, P.C., Huang, P.H., Eds.; Fengshan Tropical Horticultural Experiment Branch: Kaohsiung, Taiwan, 2015 ; pp. 73-78.

12. Liu, P.C.; Tsai, S.H.; Yen, C.R. Pitaya breeding strategies for improving commercial potential in Taiwan. In Improving Pitaya Production and Marketing, Proceedings of the Workshop on Improving Pitaya Production and Marketing, Kaohsiung, Taiwan, 7-9 September 2015; Fengshan Tropical Horticultural Experiment Branch: Kaohsiung, Taiwan, 2015; pp. 65-71.

13. Chu, Y.C.; Chang, J.C. Codification and description of the phenological growth stages of red-fleshed pitaya (Hylocereus polyrhizus) using the extended $\mathrm{BBCH}$ scale-with special reference to spines, areole, and flesh color development under field conditions. Sci. Hortic. 2022, 293, 110752. [CrossRef] 
14. Cheng, C.M.; Weng, S.W. Studies on pollen morphology and activity of pitaya (Hylocereus undatus Britt. \& rose). Hortic. NCHU 2000, 25, 13-25.

15. Chien, Y.C.; Chang, J.C. Net houses effects on microclimate, production, and plant protection of white-fleshed pitaya. HortScience 2019, 54, 692-700. [CrossRef]

16. Chen, Y.C.; Lin, Y.Y. Research on preventing sunburn damages on the cladodes of pitaya by shading treatments. Res. Bull. Taitung Dist Agric. Improv. Sta. 2016, 26, 41-58.

17. Chang, P.T.; Hsieh, C.C.; Jiang, Y.L. Responses of 'Shih Huo Chuan'pitaya (Hylocereus polyrhizus (Weber) Britt. \& Rose) to different degrees of shading nets. Sci. Hortic. 2016, 198, 154-162.

18. Chu, Y.C.; Lee, W.H.; Chang, J.C. Sustaining and improving pitaya production in abiotic stress environments: A case study in Penghu, Taiwan. In Improving Pitaya Production and Marketing, Proceedings of the Workshop on Improving Pitaya Production and Marketing, Kaohsiung, Taiwan, 7-9 September 2015; Jiang, Y.L., Liu, P.C., Huang, P.H., Eds.; Fengshan Tropical Horticultural Experiment Branch: Kaohsiung, Taiwan, 2015; p. 181.

19. Maxwell, K.; Johnson, G.N. Chlorophyll fluorescence-A practical guide. J. Exp. Bot. 2000, 51, 659-668. [CrossRef] [PubMed]

20. Li, Y.Y. Chlorophyll Fluorescence as an Indicator to Evaluate Temperature Stress of Papaya (Carica papaya L.). Master's Thesis, National Chung Hsing University, Taichung, Taiwan, 2012.

21. Ho, M.-C. Chlorophyll fluorescence as an indicator to evaluate temperature stress of guava (Psidium guajava L.). Master's Thesis, National Chung Hsing University, Taichung, Taiwan, 2014.

22. Yamada, M.; Hidaka, T.; Fukamachi, H. Heat tolerance in leaves of tropical fruit crops as measured by chlorophyll fluorescence. Sci. Hortic. 1996, 67, 39-48. [CrossRef]

23. Weiss, J.; Nerd, A.; Mizrahi, Y. Flowering behavior and pollination requirements in climbing cacti with fruit crop potential HortScience 1994, 29, 1487-1492. [CrossRef]

24. Raveh, E.; Gersani, M.; Nobel, P.S. $\mathrm{CO}_{2}$ uptake and fluorescence responses for a shade-tolerant cactus Hylocereus undatus under current and doubled $\mathrm{CO}_{2}$ concentrations. Physiol. Plant. 1995, 93, 505-511. [CrossRef]

25. Zinn, K.E.; Tunc-Ozdemir, M.; Harper, J.F. Temperature stress and plant sexual reproduction: Uncovering the weakest links. $J$. Exp. Bot. 2010, 61, 1959-1968. [CrossRef]

26. Radin, J.W.; Lu, Z.; Percy, R.G.; Zeiger, E. Genetic variability for stomatal conductance in Pima cotton and its relation to improvements of heat adaptation. Proc. Natl. Acad. Sci. USA 1994, 91, 7217-7221. [CrossRef] [PubMed]

27. Jagadish, S.V.K.; Craufurd, P.Q.; Wheeler, T.R. High temperature stress and spikelet fertility in rice (Oryza sativa L.). J. Exp. Bot. 2007, 58, 1627-1635. [CrossRef] [PubMed]

28. Wu, P.L. Studies on overcoming fruiting barrier of 'Da Hong' pitaya under high temperature and degreening enhancement of 'Fremont' mandarin. Master's Thesis, National Chung Hsing University, Taichung, Taiwan, 2020.

29. Higuchi, H.; Utsunomiya, N.; Sakuratani, T. High temperature effects on cherimoya fruit set, growth and development under greenhouse conditions. Sci. Hortic. 1998, 77, 23-31. [CrossRef]

30. Wang, X.; Xiao, D.X.; Liu, Y.; Liu, M.Z. Microsporogenesis and development of male gamete in Hylocereus undatus. J. Fruit Sci. 2007, 24, 541-544.

31. Müller, F.; Rieu, I. Acclimation to high temperature during pollen development. Plant Reprod. 2016, 29, 107-118. [CrossRef]

32. Tamaki, M.; Urasaki, N.; Sunakawa, Y.; Motomura, K.; Adaniya, S. Seasonal variations in pollen germination ability, reproductive function of pistils, and seeds and fruit yield in papaya (Carica papaya L.) in Okinawa. J. Jpn. Soc. Hortic. Sci. 2011, 80, 156-163. [CrossRef]

33. Metz, C.; Nerd, A.; Mizrahi, Y. Viability of pollen of two fruit crop cacti of the genus Hylocereus is affected by temperature and duration of storage. HortScience 2000, 35, 199-201. [CrossRef]

34. Sato, S.; Peet, M.M.; Gardner, R.G. Formation of parthenocarpic fruit, undeveloped flowers and aborted flowers in tomato under moderately elevated temperatures. Sci. Hortic. 2001, 90, 243-254. [CrossRef]

35. Westwood, M.N. Temperate-Zone Pomology: Physiology and Culture, 3rd ed.; Timber Press: Portland, OR, USA, 1993; ISBN 1604690704

36. Magalhães, D.S.; Ramos, J.D.; Pio, L.A.S.; de Barros Vilas Boas, E.V.; Pasqual, M.; Rodrigues, F.A.; Rufini, J.C.M.; dos Santos, V.A. Physical and physicochemical modifications of white-fleshed pitaya throughout its development. Sci. Hortic. 2019, 243, 537-543. [CrossRef]

37. Huang, S.T.; Lin, H.L. Compositional changes in the fruit and cladode of Hylocereus undatus during fruit growth and maturation. J. Taiwan Soc. Hortic. Sci. 2009, 55, 31-42.

38. Huang, S.H. The development status of dragon fruit bagging and the effects of fruit bagging effect. Res. Bull. Tainan Dist Agric. Improv. Sta. 2020, 114, 8-13.

39. Liu, M.L. Application of chlorophyll fluorescence in selection of crop heat tolerance. Res. Bull. KDARES 2012, 21, 1-15. 